\title{
Assessment of animal African trypanosomiasis (AAT) vulnerability in cattle-owning communities of sub-Saharan Africa
}

\author{
H. R. Holt ${ }^{1,2^{*}}$, R. Selby ${ }^{3}$, C. Mumba ${ }^{4}$, G. B. Napier ${ }^{5}$ and J. Guitian ${ }^{1,2}$
}

\begin{abstract}
Background: Animal African trypanosomiasis (AAT) is one of the biggest constraints to livestock production and a threat to food security in sub-Saharan Africa. In order to optimise the allocation of resources for AAT control, decision makers need to target geographic areas where control programmes are most likely to be successful and sustainable and select control methods that will maximise the benefits obtained from resources invested.

Methods: The overall approach to classifying cattle-owning communities in terms of AAT vulnerability was based on the selection of key variables collected through field surveys in five sub-Saharan Africa countries followed by a formal Multiple Correspondence Analysis (MCA) to identify factors explaining the variations between areas. To categorise the communities in terms of AAT vulnerability profiles, Hierarchical Cluster Analysis (HCA) was performed.

Results: Three clusters of community vulnerability profiles were identified based on farmers' beliefs with respect to trypanosomiasis control within the five countries studied. Cluster 1 communities, mainly identified in Cameroon, reported constant AAT burden, had large trypanosensitive (average herd size $=57$ ) communal grazing cattle herds. Livestock (cattle and small ruminants) were reportedly the primary source of income in the majority of these cattle-owning households (87.0\%). Cluster 2 communities identified mainly in Burkina Faso and Zambia, with some Ethiopian communities had moderate herd sizes (average $=16$ ) and some trypanotolerant breeds (31.7\%) practicing communal grazing. In these communities there were some concerns regarding the development of trypanocide resistance. Crops were the primary income source while communities in this cluster incurred some financial losses due to diminished draft power. The third cluster contained mainly Ugandan and Ethiopian communities which were mixed farmers with smaller herd sizes (average $=8$ ). The costs spent diagnosing and treating AAT were moderate here.

Conclusions: Understanding how cattle-owners are affected by AAT and their efforts to manage the disease is critical to the design of suitable locally-adapted control programmes. It is expected that the results could inform priority setting and the development of tailored recommendations for AAT control strategies.
\end{abstract}

Keywords: Animal African trypanosomiasis, Sub-Saharan Africa, Cattle, Tsetse, Vulnerability assessment

\footnotetext{
* Correspondence: hholt@rvc.ac.uk

${ }^{1}$ London Centre for Neglected Tropical Disease Research, London, UK

${ }^{2}$ Department of Production and Population Health, Royal Veterinary College,

Hawkshead Lane, North Mymms, Hatfield, Hertfordshire AL9 7TA, UK

Full list of author information is available at the end of the article
} 


\section{Background}

Tsetse (Glossina spp.) and animal African trypanosomiasis (AAT) are an important constraint to livestock production and a threat to food security in sub-Saharan Africa [1]. The production losses in cattle due to trypanosome infections have been estimated to be up to $20 \%$ across a range of parameters, including mortality, calving rate, draft power, meat and milk production [2]. A high tsetse-trypanosome burden constrains the use of land for livestock production, with farmers in these areas often being more reliant on crop farming. However, trypanosomiasis also compromises crop production by reducing the availability of draft animals to plough fields and provide manure for fertiliser [2].

The impact of AAT can be reduced by trypanocide application and the introduction of trypanotolerant cattle breeds. There is no vaccine available for the disease, and reduction in transmission rates is largely reliant on control of the tsetse vector by methods such as insecticide treatment of cattle (ITC), the use of traps or targets, ground or aerial insecticide spraying, or reducing the risk of exposure through changes in livestock management. The process of privatisation of veterinary services in many sub-Saharan African countries means that farmers and community animal health workers (CAHW) with limited training are often responsible for the treatment of the disease [3]. Traditionally, farmer-based control of AAT has relied heavily on the individual use of chemotherapy and chemoprophylaxis, while methods requiring collective action have often been neglected. Trypanosome species, however are becoming increasingly resistant to these common-place treatments $[4,5]$.

In recognition of the need for co-ordinated actions against AAT, the Pan-African tsetse and trypanosome eradication campaign (PATTEC), funded by the African Development Bank, was established in the year 2000 and has set tsetse elimination as its goal. Although this goal presents a huge challenge that would require extensive resources and there is debate as to whether it is feasible, the last decade has seen renewed interest in the research and development of control options. Governments, charities and philanthropists have made funding available for this purpose, despite this, the reality is that many of the communities afflicted by AAT have insufficient resources available for its control and are not always reached by control programmes. In addition, macro-level decision making may ignore important heterogeneities between communities.

In order to optimise the allocation of resources for AAT control, decision makers target geographic areas where control programmes are most likely to be technically, economically, socially and environmentally sustainable and select methods of control that will maximise the benefits obtained from resources invested [6]. To this end, there is increasing interest in the development of decision-support tools for AAT control. These can be based on a description and analysis of geographical features by means of geographic information systems $[7,8]$, economic analysis [9, 10], modelling tsetse population dynamics [11] or a combination of these tools [6, 12]. However, the feasibility of applying such tools at locallevel may be compromised by the skill and resource base of potential end-users and data availability. Recently, relatively simple frameworks have been proposed to identify the most appropriate control options for AAT based on a small number of 'key' indicators of the ecoepidemiological cycle and the cattle rearing system [13]. Although these are useful tools, the impact that AAT has on a community is the result of complex interactions between environmental, political, socio-cultural, entomological and livestock management factors [13]. As a result, further development of existing decision tools, to reflect not only the biological, environmental or technical applicability of disease control, but also the likely impacts on the communities living within affected areas is warranted so that control programmes reach those who are most vulnerable. This study was therefore carried out to use cattle owner interview data to perform a community-level vulnerability assessment, to add to the growing body of evidence for decision making regarding AAT control by identifying typologies or profiles of the communities in terms of their AAT vulnerability. It is expected that the results could inform priority setting and the development of tailored recommendations for AAT control strategies

\section{Methods}

A series of interviews were conducted with cattle owners in different agro-ecological zones across five countries in sub-Saharan Africa, namely Burkina Faso, Cameroon, Ethiopia, Uganda and Zambia. Data collected on cattle was mainly on owners' knowledge and perceptions of AAT. The study sites provided a large variation in environment, AAT eco-epidemiology, cattle management and socio-economic impact of AAT. The overall approach to classifying communities in terms of AAT vulnerability was based on the selection of key variables collected through field surveys followed by a formal Multiple Correspondence Analysis (MCA) to identify factors explaining the variation between areas. Hierarchical Cluster Analysis (HCA) was then performed in order to categorise communities into groups describing their AAT vulnerability profile.

\section{Field surveys}

A series of surveys were conducted in 17 study areas in five countries in sub-Saharan African during 2013; Burkina Faso, Cameroon, Ethiopia, Uganda and Zambia. 
A previous review of tsetse density and trypanosome prevalence studies was the basis for the geographic focus of the study, identifying the selected countries as moderate to high risk AAT areas. The countries were also selected to cover a range of eco-regions and AAT epidemiology, in addition the ease of conducting fieldwork in the selected countries was taken into account. Within the countries, study areas were classified in terms of environment, including ecoregion and available information on AAT risk. A brief description of the study areas is given below and in Table 1 .

\section{Burkina Faso}

The main income in these study areas comes from rain fed agriculture with cattle utilised for draft power. Livestock rearing in extensive systems is also common; however trypanosomiasis is a constraint to livestock production in the area. AAT is endemic, and cattle owners report it as the most important disease in tsetse challenged areas [14]. Resistance to trypanocides is thought to be widespread, particularly isometamidium resistant $T$. congolense, and the first reports of trypanocide resistance came from these study areas [5]. The Léraba study area is crossed by 32,000 cattle per year from the North of Burkina Faso and Mali en route to markets in Côte d'Ivoire. In addition, during the dry season there is transhumance of Fulani cattle into the areas due to the availability of water points. Cattle entering the area may be highly susceptible to AAT.

\section{Cameroon}

The study was conducted in the Adamawa plateau which is the most important cattle rearing region in Cameroon. Here, white and red Fulani cattle are reared extensively, with a system of communal herding and Gudali (Sahelian Zebu) cattle are also important in the region. There is risk of AAT infection in at least two-thirds of the territory where $90 \%$ of the cattle are found and the disease is one of the biggest limitations to the development of the cattle sector in Cameroon [15]. In 1995, at the end of the tsetse eradication campaign initiated by the government-founded 'Mission spéciale pour léradication des glossines'(MSEG), the Faro et Déo division of the Adamawa plateau was divided into three zones: tsetse infested, tsetse cleared and a buffer zone between the two zones where all the cattle are treated with pyrethroids at regular intervals [16]. In 2010, a report from the Cameroonian government estimated that in tsetse infested zones, milk and meat sales were reduced by $50 \%$ [15].

\section{Ethiopia}

Tsetse infest around $220,000 \mathrm{~km}^{2}$ of fertile land in south and southwestern parts of Ethiopia [8, 17]. AAT is thought to be the most important livestock disease in terms of economic development and influence on settlements [18]. AAT has also been reported as an important disease in other species especially in equines and goats [19]. The surveys were conducted in the Jimma zone of the Oromia region which is known for its large cattle numbers and the economy is also heavily reliant on crop production [18]. In this

Table 1 Brief description of the study areas based on previous tsetse \& trypanosome information. Note: survey estimates in cattle were not necessarily from representative samples (hh's = households)

\begin{tabular}{|c|c|c|c|c|c|c|}
\hline Countries & Study areas & $H H^{\prime} \mathrm{s}$ & Trypanosome cattle (\%) & Trypanosome species & Tsetse species & Ref \\
\hline \multirow[t]{3}{*}{ Burkina Faso } & loba \& Sissili & 123 & $4.3 \%$ to $10 \%$ & \multirow{3}{*}{$\begin{array}{l}\text { T. vivax, T. congolense and } \\
\text { T.brucei brucei }\end{array}$} & \multirow{3}{*}{$\begin{array}{l}\text { G. pallidipes gambiensis, } \\
\text { G.tachinoides \& G. morsitans } \\
\text { submorsitans }\end{array}$} & \multirow[t]{3}{*}[4]{} \\
\hline & Kénédougou & 61 & & & & \\
\hline & Léraba & 41 & & & & \\
\hline \multirow[t]{3}{*}{ Cameroon } & North Faro \& Faro et Deo & 131 & $35.1 \%$ & \multirow{3}{*}{$\begin{array}{l}\text { T. congolense, T. brucei \& } \\
\text { T. vivax. }\end{array}$} & \multirow{3}{*}{$\begin{array}{l}\text { G. } m \text { submortisans, G. fuscipes } \\
\text { fuscipes \& G. tachinoides }\end{array}$} & \multirow[t]{3}{*}[49,50]{} \\
\hline & South Faro & 91 & $4.3 \%$ & & & \\
\hline & Mayo Rey & 77 & $9.86 \%$ & & & \\
\hline \multirow[t]{4}{*}{ Ethiopia } & Goma \& Setema & 45 & $8.6 \%-20.4 \%$ & \multirow{4}{*}{$\begin{array}{l}\text { T. congolense, T. vivax, } \\
\text { T. b. brucei, T. evansi }\end{array}$} & \multirow{4}{*}{$\begin{array}{l}\text { G. fuscipes, G. pallidipes, G. m. } \\
\text { submortisans, G. tachinoides, } \\
\text { \& G. longipennis }\end{array}$} & \multirow[t]{4}{*}[31,51,52]{} \\
\hline & Goro \& Cheha & 36 & & & & \\
\hline & Limmu Seka (East) & 34 & & & & \\
\hline & Limmu Seka (West) & 36 & & & & \\
\hline \multirow[t]{4}{*}{ Uganda } & Tororo & 139 & $15.3 \%$ & \multirow{4}{*}{$\begin{array}{l}\text { T. vivax, } T \text {. congolense \& } \\
\text { T. brucei. rhodesiense }\end{array}$} & \multirow{4}{*}{$\begin{array}{l}\text { G. f. fuscipes, G. pallidipes \& } \\
\text { G. morsitans }\end{array}$} & \multirow[t]{4}{*}[21,22]{} \\
\hline & Buyende \& Pallisa & 78 & $27.5 \%-35.7 \%$ & & & \\
\hline & Kumi \& Ngora & 83 & $29.0 \%$ & & & \\
\hline & Busia \& Iganga & 74 & & & & \\
\hline \multirow[t]{3}{*}{ Zambia } & Lundazi - plateau & 99 & & \multirow{3}{*}{$\begin{array}{l}\text { T. vivax, T. congolense \& } \\
\text { T. brucei }\end{array}$} & \multirow{3}{*}{$\begin{array}{l}\text { G. m submortisans, G. pallidipes, } \\
\text { G. breval papis, G. f. fuscipes \& } \\
\text { G. tachinoides }\end{array}$} & \multirow[t]{3}{*}{ [53] } \\
\hline & Lundazi - valley & 57 & $17.8 \%$ & & & \\
\hline & Mambwe & 54 & $28.4 \%$ & & & \\
\hline
\end{tabular}


region cattle farmers attribute reductions in draft power and meat and milk offtake, increased calving intervals and mortalities and impacts on breeds kept and cattle management to AAT [18] .

\section{Uganda}

In Uganda the 'tsetse belt' runs from the highlands in southwestern Uganda across Lake Kyoga to north-eastern Uganda and at least $70 \%$ of the entire country is thought to be infested with tsetse flies [20]. T. vivax is the most prevalent species of trypanosome in Ugandan cattle and $T$. congolense and T. brucei rhodesiense infections also occur $[21,22]$. Following increases in human density, changes in land use, and a reduction in the wildlife population, Ugandan cattle are now considered the primary host of $T . b$. rhodesiense [23]. T. b. rhodesiense causes human African trypanosomiasis (HAT) or 'sleeping sickness' which is fatal if left untreated. The distribution of $T . b$. rhodesiense in Uganda has increased dramatically in the past 10 years; this is attributed to the restocking of infected cattle into naïve areas following military conflict in the late 1990's [22]. Over $50 \%$ of reported T. $b$. rhodesiense cases in the whole of Africa between 2000 and 2009 were from Uganda [24]. The study was conducted in the Southeast region of Uganda.

\section{Zambia}

The Luangwa valley runs through the Eastern Province of Zambia, with 3.84 million hectares of national park (46.9\%) and 0.41 million ha dedicated game management area the valley is an ecological niche for trypanosomes allowing vector-host interaction due to favourable conditions for tsetse in terms of vegetation, climate and abundance of wildlife hosts [25]. The study was conducted in Lundazi and Mambwe districts in the Eastern Province as there were reports of AAT, and cooperation with district veterinarians. Lundazi has a human population density of 22.4 people $/ \mathrm{km}^{2}$ whilst Mambwe has a population density of approximately 13.4 people $/ \mathrm{km}^{2}$. An increase in pressure on natural resources in the plateau area of the district has led to the relocation and expansion of the human population into the edges of the Luangwa valley expanding the wildlife-livestock interface. HAT cases have also occurred in the valley [26].

\section{Selection of communities and households}

Study areas were selected using random sampling from a sample frame of all communities within selected administrative divisions of each of the study countries. Within 195 communities 1,259 households across the five countries were visited during the course of the study. A household was defined as a group of people who usually reside and eat together. The head of the household was interviewed using a pre-piloted questionnaire which contained general questions about their herd, access to veterinary products and services, and livestock diseases. They were then asked questions specifically about AAT in an attempt to assess the relative importance of the disease to farmers. These questions focused on what is currently known, done and perceived with regards to AAT and its control. The study-unit for this analysis was the community; therefore the results from individual households were aggregated at community level.

\section{Selection of variables}

The vulnerability of a community has been defined as a product of exposure, sensitivity and capacity to adapt when an extreme event takes place [27]. We consider exposure to AAT as the risk of AAT occurrence in the community which is influenced by climatic factors and the eco-epidemiology of the disease in the area. Sensitivity is defined by factors influencing the potential impact of AAT in the community, for example the susceptibility of cattle breeds, and the relative importance of cattle. Adaption refers to current measures to reduce the impact of the disease, either through the actions of farmers, governments or local authorities.

The first step for the MCA was to identify variables likely to be associated with the exposure, sensitivity and adaption to AAT in an area. This was done using existing literature and the available field data. It was based on two principal criteria: firstly, the relevance of variables to the objective of the assessment and secondly the completeness of data collected. The resulting variable selection is detailed in Table 2.

\section{Multiple correspondence analysis (MCA) and cluster analysis} MCA is a data reduction technique (similar to factor analysis or principle components analysis) which allows complex patterns in a dataset of categorical variables to be identified. Briefly, MCA provides a graphic representation describing the relationships between categories of variables and creates factors which describe the variation in the data. This technique also allows variables exhibiting little variation between the communities to be excluded and those which vary the most between communities to be identified. This technique has previously been used to identify biosecurity profiles of farms $[28,29]$.

MCA was performed on the selected variables at community level using the Indicator method. The coordinates of each community were calculated on three dimensions explaining $47.1 \%$ of the variance and HCA was then performed on the selected dimensions using Ward's method to aggregate areas into relatively homogeneous subgroups or profiles. These profiles maximise inter-cluster variation and intra-cluster correlation. The analysis was performed using the package FactoMineR in R v. 3.0.1. 
Table 2 Variables selected for inclusion in the MCA, and there classifications

\begin{tabular}{|c|c|c|}
\hline & Variable & Classification \\
\hline \multirow[t]{2}{*}{ Exposure } & Perceived incidence in the community & $\begin{array}{l}\text { Whether the majority of cattle-owners reported AAT challenge as } \\
\text { "rare", "frequent" or "constant" }\end{array}$ \\
\hline & Seasonality & $\begin{array}{l}\text { Whether the majority of cattle-owners reported a seasonal effect } \\
\text { of AAT }\end{array}$ \\
\hline \multirow[t]{6}{*}{ Sensitivity } & Cattle breeds & $\begin{array}{l}\text { Whether any cattle-owners owned Bos Indicus (trypanotolerant) or } \\
\text { crossbreeds (partial trypanotolerance) }\end{array}$ \\
\hline & Main cattle rearing systems & $\begin{array}{l}\text { Whether farmers in the community were practicing tethering in } \\
\text { addition to communal-grazing }\end{array}$ \\
\hline & Tsetse control present & $\begin{array}{l}\text { Whether at least } 40 \% \text { of cattle-owning households reported existence } \\
\text { of any form of tsetse control method in the community }\end{array}$ \\
\hline & Herd size & Average herd size in the community classified into 3 bins of equal size \\
\hline & Treatment failure & $\begin{array}{l}\text { Whether the majority of farmers reported that treatment failure is } \\
\text { "never" "rare" or "frequent" }\end{array}$ \\
\hline & Treatment & $\begin{array}{l}\text { Whether farmers report that they treat the disease themselves, or } \\
\text { whether they rely on trained animal health workers, veterinary } \\
\text { assistants or similar. }\end{array}$ \\
\hline \multirow[t]{6}{*}{ Capacity to adapt } & Insecticide treated cattle (ITC) & $\begin{array}{l}\text { Whether cattle-owning households reported the use of ITC as a } \\
\text { measure of tsetse control in the community }\end{array}$ \\
\hline & Tsetse control present & $\begin{array}{l}\text { Whether cattle-owning households reported existence of any tsetse } \\
\text { trapping in the community }\end{array}$ \\
\hline & Farmer knowledge of AAT control & $\begin{array}{l}\text { Whether the majority of farmers could recognise a picture of a tsetse } \\
\text { trap and/or name tsetse control measures }\end{array}$ \\
\hline & Losses to draft & $\begin{array}{l}\text { Whether the majority of cattle-owning households report that AAT } \\
\text { impacts their livelihood due to reductions in draft power }\end{array}$ \\
\hline & Reported mortalities & $\begin{array}{l}\text { Average number of mortalities reported by cattle owning households } \\
\text { categorised into three bins }\end{array}$ \\
\hline & Importance of cattle in the community & $\begin{array}{l}\text { Whether the majority of cattle-owning households ( }>60 \% \text { ) reported } \\
\text { livestock as the primary agricultural income source, or if cropping } \\
\text { or mixed farming systems are considered more important }\end{array}$ \\
\hline
\end{tabular}

\section{Results and discussion}

\section{Results of the multiple correspondence analysis}

Dimensions 1 and 2 from the results of the MCA of variables associated with AAT vulnerability are presented in Figs. 1 and 2. The importance of cattle in the community had the highest loadings on both dimensions with rearing method, herd size, perceived incidence and whether or not tsetse trapping was reported contributing the most to the formation of dimension 1. Frequency of treatment failure, whether

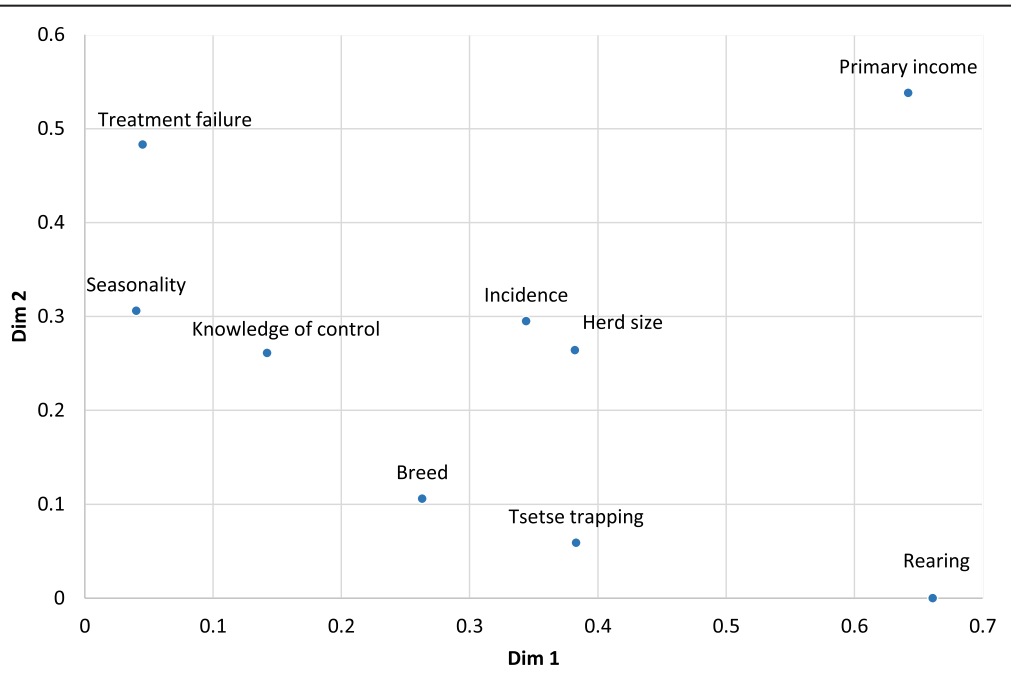

Fig. 1 contribution of the variables to the formation of dimensions 1 and 2 


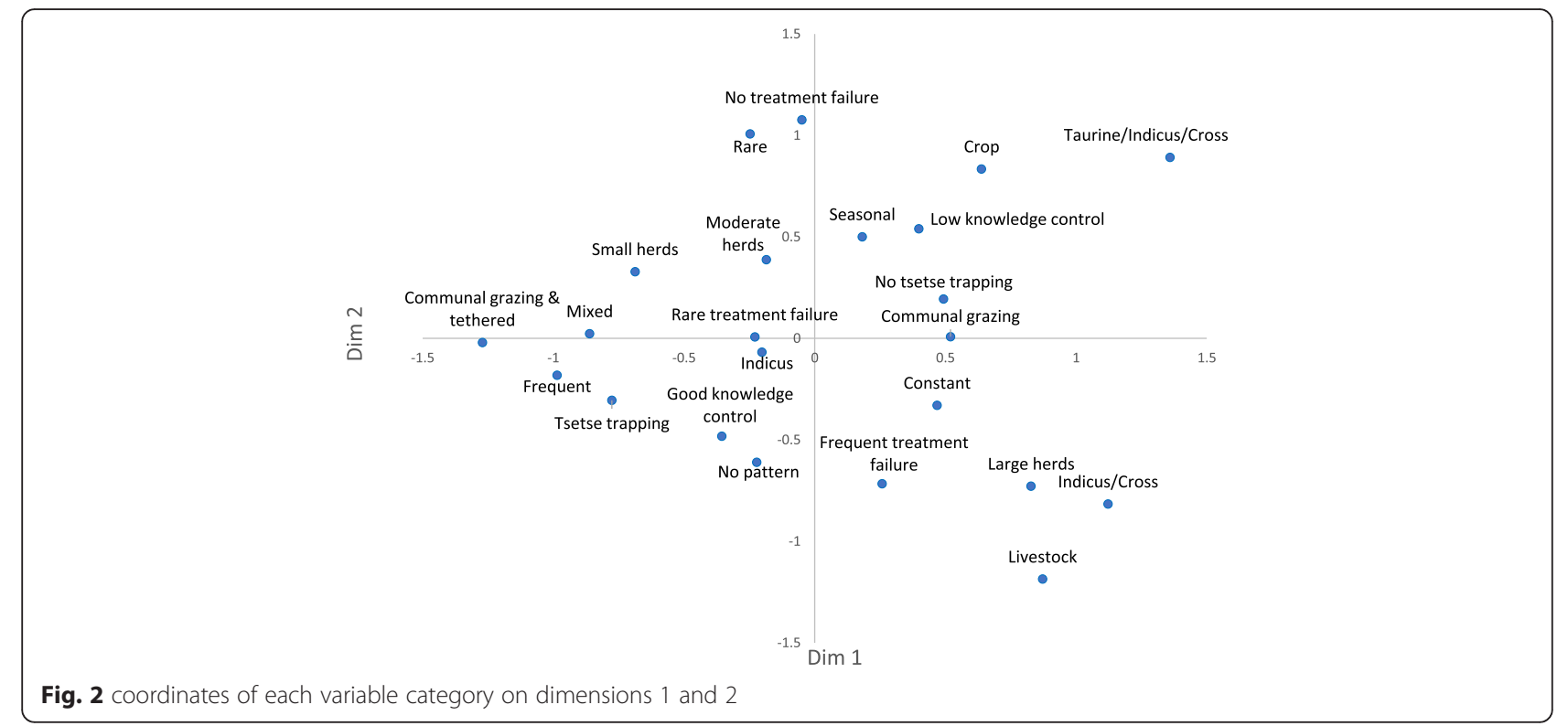

cattle-owners felt the disease exhibited seasonal pattern, perceived incidence and herd size had the highest loadings on dimension 2. Mortality, who treats AAT (farmers' vs. animal health workers) and whether ITC is used in the community were excluded because they had low loadings on all synthetic dimensions. The coordinates of the variables for dimension 1 and 2 , which explained the largest percentage of the variation, are presented in Fig. 2.

\section{Results of the cluster analysis}

The rural communities in this study were classified into three profiles or clusters (Fig. 3 and Table 3), which maximise inter vs. intra-cluster variation. Cluster 1 is characterised by the variables in the bottom right quadrant of Fig. 2, these communities reported constant AAT challenge (87.0 \%) with no seasonal pattern (71.7\%). Most herds were trypanosensitive (87.0 \%) (Red and White Fulani and some Gudali) and all practiced communalgrazing, although some communities reported keeping Zebu x Taurine cross-breeds in addition to local Zebu's which have some trypanotolerance (13.0\%). These communities had larger herd sizes (average $=57$ ) and cattleowners were also more likely to report livestock farming as their primary source of income $(87.0 \%)$. Although the majority of communities appeared to have good knowledge of tsetse control (63.0\%), tsetse trapping was not reported in the area $(80.4 \%)$. These communities were most likely to

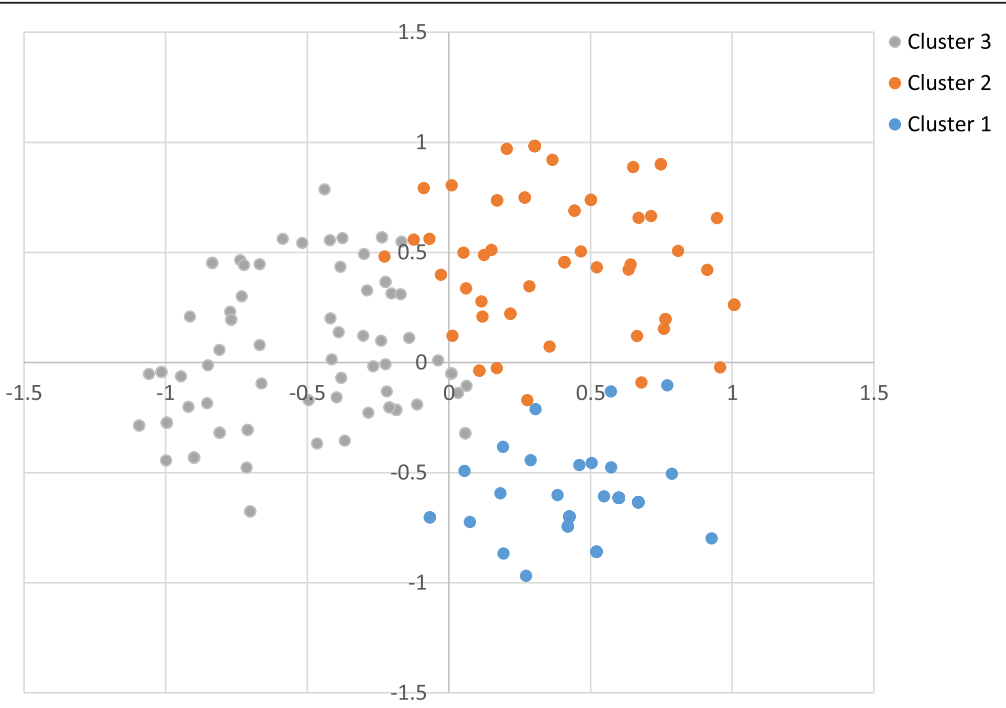

Fig. 3 coordinates of each community on dimensions 1 and 2 and their cluster 
Table 3 distribution of the variables retained in the final MCA and HCA, according to cluster

\begin{tabular}{|c|c|c|c|}
\hline & Cluster 1 & Cluster 2 & Cluster 3 \\
\hline \multicolumn{4}{|l|}{ AAT challenge } \\
\hline AAT constant & $87.0 \%$ & $60.0 \%$ & $37.9 \%$ \\
\hline AAT frequent & $8.7 \%$ & $6.7 \%$ & $37.9 \%$ \\
\hline AAT rare & $4.3 \%$ & $33.3 \%$ & $24.1 \%$ \\
\hline \multicolumn{4}{|l|}{ Seasonality } \\
\hline No pattern & $71.7 \%$ & $16.7 \%$ & $50.6 \%$ \\
\hline Seasonal & $28.3 \%$ & $83.3 \%$ & $49.4 \%$ \\
\hline \multicolumn{4}{|l|}{ Breeds kept } \\
\hline Indicus & $87.0 \%$ & $66.7 \%$ & $100 \%$ \\
\hline Indicus/Cross & $13.0 \%$ & $1.7 \%$ & - \\
\hline Taurine/Indicus/Cross & - & $31.7 \%$ & - \\
\hline \multicolumn{4}{|l|}{ Livestock rearing (day) } \\
\hline Communal grazing & $100 \%$ & $98.3 \%$ & $36.8 \%$ \\
\hline Communal \& tethered & - & $1.7 \%$ & $63.2 \%$ \\
\hline \multicolumn{4}{|l|}{ Average herd size } \\
\hline Small $(<7)$ & $2.2 \%$ & $18.3 \%$ & $52.9 \%$ \\
\hline Moderate (7 to 13 ) & $4.3 \%$ & $55.0 \%$ & $41.4 \%$ \\
\hline Large (>13) & $93.5 \%$ & $26.7 \%$ & $5.7 \%$ \\
\hline \multicolumn{4}{|l|}{ Treatment failure } \\
\hline No treatment failure & $2.2 \%$ & $45.0 \%$ & $23.0 \%$ \\
\hline Rare treatment failure & $28.3 \%$ & $31.7 \%$ & $46.0 \%$ \\
\hline Frequent treatment failure & $69.6 \%$ & $23.3 \%$ & $31.0 \%$ \\
\hline \multicolumn{4}{|l|}{ Primary income } \\
\hline Crop & $2.2 \%$ & $83.3 \%$ & $10.3 \%$ \\
\hline Livestock & $87.0 \%$ & $1.7 \%$ & $3.4 \%$ \\
\hline Mixed & $10.9 \%$ & $15.0 \%$ & $86.2 \%$ \\
\hline \multicolumn{4}{|l|}{ Knowledge of tsetse control } \\
\hline Good knowledge control & $63.0 \%$ & $20.0 \%$ & $70.1 \%$ \\
\hline Low knowledge control & $37.0 \%$ & $80.0 \%$ & $29.9 \%$ \\
\hline \multicolumn{4}{|l|}{ Tsetse trapping community } \\
\hline No tsetse trapping & $80.4 \%$ & $90.0 \%$ & $31.0 \%$ \\
\hline Tsetse trapping & $19.6 \%$ & $10.0 \%$ & $69.0 \%$ \\
\hline
\end{tabular}

report frequent treatment failure (69.6\%), and contained $91.1 \%$ of the communities from Cameroon (Table 4).

All of the communities which kept some trypanotolerant breeds (Boulé) and Métis crossbreeds were found in cluster $2(31.7 \%)$ and these were mainly communities located in Burkina Faso. This cluster is found in the top right quadrant of Figs. 2 and 3. Most communities practiced communal-grazing (98.3\%) and crop production tended to be the most important income source $(83.3 \%)$, followed by mixed farming. These communities had the lowest awareness of tsetse control measures with $80.0 \%$ not identifying tsetse traps or
Table 4 distribution of the communities according to country and cluster

\begin{tabular}{lccc}
\hline Country & Cluster 1 & Cluster 2 & Cluster 3 \\
\hline Burkina Faso & $4.8 \%$ & $95.2 \%$ & - \\
Cameroon & $91.1 \%$ & $8.9 \%$ & - \\
Ethiopia & $8.7 \%$ & $30.4 \%$ & $60.9 \%$ \\
Uganda & $2.7 \%$ & $6.6 \%$ & $90.4 \%$ \\
Zambia & - & $77.4 \%$ & $22.6 \%$ \\
\hline
\end{tabular}

naming tsetse control methods. Communities reported "never" experiencing treatment failure (45.0 \%), although this is subjective. All communities in cluster 3 kept trypanosensitive Zebu breed but most of them practiced communal-grazing and tethering (63.2\%). The majority of farming was mixed i.e., livestock and crop farming of similar importance (86.2\%). Communities were most likely to report some tsetse control (69.0\%) and knowledge of AAT control tended to be good $(70.1 \%)$. Treatment failure was mostly reported as "rare" (46.0 \%) in these communities. This cluster is described in the bottom left hand side of Figs. 2 and 3 .

\section{Results of the cluster analysis: supplementary variables}

We then investigated the difference between selected supplementary variables and membership of the different clusters (Table 5). The majority of communities did not report using ITC, (>80 \% in every cluster). Communities in cluster 1 were most likely to believe that centralised governments $(67.4 \%)$ or NGO's (17.4\%) were responsible for control. With cluster 2 and 3 more likely to name district officials or individuals.

When asked about diagnosis and treatment, farmers were most likely to be responsible for both in cluster 1 (diagnosis: $89.1 \%$, treatment: $73.9 \%$ ). With between a half and two-thirds of communities reportedly using trained individuals for diagnosis and treatment in clusters 2 and 3. Trypanocidal resistance was reported as a possible reasons for treatment failure in clusters 2 $(63.3 \%)$ and $3(57.5 \%)$. Drug quality was also a concern of farmers in clusters 1 (60.9 \%) and 3 (37.9 \%). Communities appeared to spend the most diagnosing and curatively treating AAT in cluster 1 with $63.0 \%$ reportedly spending an average of 55 or more US\$ in the past two years. Communities in cluster 2 appeared to have incurred the lowest costs with $42.5 \%$ spending less than 15 US\$ over the same time period.

In terms of herd sizes, cluster 1 communities tended to have larger numbers of cows $(82.6 \%>10)$, castrated males $(47.8 \%>2)$, uncastrated males $(71.7 \%>4)$ and calves $(80.4 \%>4)$. Sheep were kept by around $90 \%$ of these communities but they were less likely to keep goats $(43.5 \%=$ zero $)$ and pigs $(91.3 \%=0)$. Cluster 2 was 
Table 5 distribution of the supplementary variables according to cluster

\begin{tabular}{|c|c|c|c|}
\hline & Cluster 1 & Cluster 2 & Cluster 3 \\
\hline \multicolumn{4}{|l|}{ ITC } \\
\hline No ITC & $82.6 \%$ & $85.0 \%$ & $83.9 \%$ \\
\hline ITC & $17.4 \%$ & $15.0 \%$ & $16.1 \%$ \\
\hline \multicolumn{4}{|l|}{ Responsible for AAT control } \\
\hline Communities & $4.3 \%$ & $16.7 \%$ & - \\
\hline Individuals & $6.5 \%$ & $33.3 \%$ & $24.1 \%$ \\
\hline District officials & $4.3 \%$ & $28.3 \%$ & $46.0 \%$ \\
\hline Centralised governments & $67.4 \%$ & $8.3 \%$ & $24.1 \%$ \\
\hline NGOs & $17.4 \%$ & $13.3 \%$ & $5.7 \%$ \\
\hline \multicolumn{4}{|l|}{ Diagnosis } \\
\hline Farmers & $89.1 \%$ & $63.3 \%$ & $50.6 \%$ \\
\hline Trained & $10.9 \%$ & $36.7 \%$ & $49.4 \%$ \\
\hline \multicolumn{4}{|l|}{ Treatment } \\
\hline Farmers & $73.9 \%$ & $43.3 \%$ & $37.9 \%$ \\
\hline Trained & $26.1 \%$ & $56.7 \%$ & $62.1 \%$ \\
\hline \multicolumn{4}{|l|}{ Reasons for treatment failure } \\
\hline Misdosing & $21.7 \%$ & $11.7 \%$ & $16.1 \%$ \\
\hline Drug quality & $60.9 \%$ & $20.0 \%$ & $37.9 \%$ \\
\hline Misdiagnosis & $30.4 \%$ & $25.0 \%$ & $28.7 \%$ \\
\hline Resistance & $30.4 \%$ & $63.3 \%$ & $57.5 \%$ \\
\hline \multicolumn{4}{|l|}{ Total cost AAT } \\
\hline Low $(<\$ 15)$ & $17.4 \%$ & $28.3 \%$ & $42.5 \%$ \\
\hline Medium ( $\$ 15$ to $\$ 55)$ & $19.6 \%$ & $40.0 \%$ & $41.4 \%$ \\
\hline High (>\$55) & $63.0 \%$ & $31.7 \%$ & $16.1 \%$ \\
\hline \multicolumn{4}{|l|}{ Cattle mortalities } \\
\hline Low & $4.3 \%$ & $4.9 \%$ & $4.7 \%$ \\
\hline Medium & $39.1 \%$ & $35.0 \%$ & $26.7 \%$ \\
\hline High & $56.5 \%$ & $61.7 \%$ & $67.4 \%$ \\
\hline \multicolumn{4}{|l|}{ Draught losses } \\
\hline No & $67.4 \%$ & $53.3 \%$ & $49.4 \%$ \\
\hline Yes & $32.6 \%$ & $46.7 \%$ & $50.6 \%$ \\
\hline
\end{tabular}

mostly composed of medium sized ( 4 to 10 adult female cows) herds. Most households in this cluster also kept sheep and goats. Most households in cluster 3 had small herds of up to three adult female cows (57.5 \%) with the rest keeping 4 to 10 , around half had sheep and were more likely to have goats than households compared to the other two clusters. These communities were the most likely to keep pigs (67.8\%), with $53.3 \%$ of farmers in cluster 2 also keeping pigs. A summary of the results is given in Fig. 4.

The results from this study were then compared to previous surveys available in the study areas (Table 1). Cluster 1 appeared to be vulnerable to AAT and prevalence's as high as $35.4 \%$ have been reported in the Adamawa Plateau study areas [30]. Burkina Faso study areas appeared to have the lowest AAT prevalence, and these communities were the most likely to be using trypanotolerant breeds [4]. Some communities in Uganda (Cluster 3) reported rare AAT occurrence, although others reported it as frequent or constant. Previous prevalence estimates of AAT in Uganda were higher than the majority of other study areas [22], however, these studies were conducted in markets and may represent a higher risk population. Cluster 3 also included Ethiopian communities, in some areas close to the study region farmers have ranked the importance of the disease as "moderate" and prevalence estimates were around $8.7 \%$. This is likely due to the establishment of the Southern Tsetse Eradication Programme (STEP) [31]. Further work is needed to assess how farmers' perceptions of the disease compare with the epidemiology of the disease in different areas.

Historically, large-scale efforts to control trypanosomiasis have focussed on elimination of the vector which requires considerable investment and detailed planning. In addition, sustained elimination is only possible when the total tsetse population is addressed, which requires either an isolated population, or the sequential eradication of a full tsetse belt $[32,33]$. Coordinated efforts between communities within and between countries are needed as well as strong political and financial support [13]. As a result, many previous elimination efforts have not been successful, or AAT has re-emerged after funding for control has waned [32]. In both Burkina Faso and Cameroon study areas, successful suppression of tsetse was achieved in the past through integrated control programmes managed by specialist government institutions, however, in both cases reinvasion occurred as control efforts were not sustained [16, 34].

In areas where sustained suppression is not currently feasible, understanding of how cattle-owners are affected by AAT and their efforts to manage the disease is critical to the design of suitable locally-adapted control programmes [13]. The variables considered in the analysis were assumed to describe the vulnerability of a community to AAT and this information could help target communities to receive support to implement control options. Given the heterogeneity across communities studied, in some communities farmers may be successful at managing the disease on their own. In clusters 2 and 3 farmers have developed some strategies to manage the disease, such as restricted grazing or the use of trypanotolerant cattle. Whereas for some cattleowning communities, for example those in cluster 1 experiencing treatment failure or high mortalities, the vulnerability may be so high that considerable external support and investment is needed to reduce the 


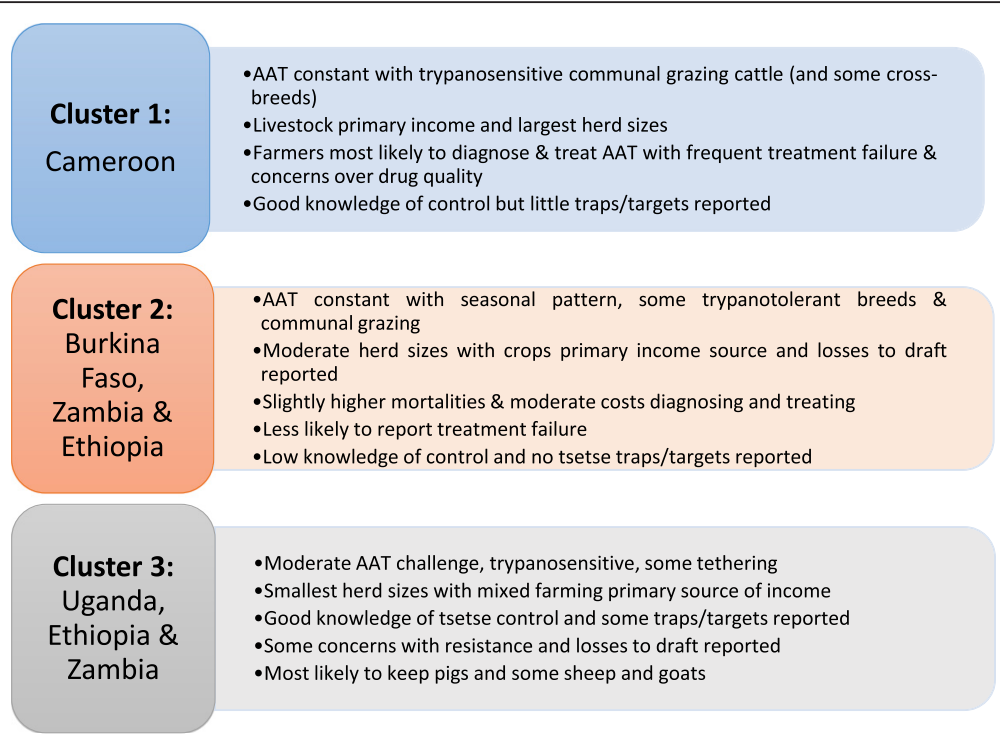

Fig. 4 overall summary of the results of selected communities in five sub-Saharan African countries based on determinants of AAT vulnerability

trypanosome burden. However, the study used data provided by cattle-owners and did not investigate parasitological prevalence or surveys of tsetse. The results should be integrated with other data e.g., recent tsetse and unbiased cattle prevalence surveys and interviews with managers of AAT control to investigate the relationship between these data sources and the burden reported by cattle-owners.

Farmers are heavily reliant on chemotherapy for AAT control [28, 35]. Trypanocide use was ubiquitous throughout the study areas and therefore showed no association with any particular cluster. In these communities there appeared to be a lack of vector control. Alternative control measures such as ITC or live bait technologies, screens, traps and targets may represent a cost-effective alternative to trypanocides [18]. Although in some communities there may have been a lack of awareness of these tsetse control methods (particularly in cluster 2), farmers' also face a collective-action dilemma when it comes to the financing and organising of community-level interventions. These areas may benefit from governmental or institutional interventions to provide community-level tsetse control or to help mobilise communities to organise themselves and adopt technologies from which all community members may benefit. Cost-recovery schemes have had some success, but depend on financial resources of the farmers and the perceived benefits of the initiative [36]. In Ethiopia a cost-recovery scheme was initiated in an area with high trypanocide resistance consisting of monthly pour-on application with cypermethrin and chemotherapy [37]. In the study area an average decrease of $57 \%$ in calf mortality (including still births) by 12 months of age and an increase of $8 \%$ in the body weight of adult males was observed [37], suggesting that the scheme was successful.

In some communities cattle production is unlikely to be sustainable due to the high tsetse-trypanosome burden and lack of herd or community-level control of the disease due to lack of resources or technical capacity [13]. In these communities, farmers explore alternative sources of income. This is the case in the valley study area of Lundazi (cluster 2), where access to markets and veterinary services are poor and farmers co-exist with an expanding wildlife and tsetse population. There are few-cattle owning households in this region, and primary source of household income tends to be from crop production. Here communities tend to keep trypanosensitive Angoni breeds whose draft power provision is greatly reduced by AAT. Some farmers in Burkina Faso managed the disease by using the trypanotolerant Métis or Baoule cattle breeds; similarly, the introduction of trypanotolerant breeds may be of benefit in Zambia. However, trypanotolerant breeds are considered to have reduced traction which is the main use of cattle in this area, although this may be offset in areas with high morbidity and mortalities in trypanosensitive draft animals [38].

Where seasonality allows, an alternative management strategy to reduce the risk of AAT is to only graze in tsetse infested areas in certain times of the year [35]. In the case of Cameroon, which was mainly represented by cluster 1 , farmers manage the disease by only entering the valley region during the dry season where AAT risk is at its lowest [16]. The majority of farmers kept trypanosensitive Fulani and Gudali cattle, therefore perhaps 
the use of trypanotolerant cattle would also reduce the impact here. Although farmers in the region have a strong cultural preference for the traditional Fulani breeds. Trypanotolerant breeds such as N'Dama of West Africa may have comparable productivity in terms of meat and milk to trypanosensitive breeds in areas where AAT burden is high, and the majority of cattle in the Cameroonian study areas are kept for this purpose [39]. Few communities kept a large proportion of trypanotolerant breeds, and those that did were mainly communities of Burkina Faso in cluster 2, it is estimated that there were 11.68 million trypanotolerant cattle in 1998 of which 11 million were in West Africa and 0.68 million in Central Africa [40].

Communities in cluster 1 reported no tsetse control, despite the Mission spéciale pour l'éradication des glossines (MSEG) running low level control operations for many years [16]. However, there are only a small number of traps and targets in the cleared area and buffer zone in the Faro et Deo region of Cameroon (personal communication: MSEG). The MSEG also report some bi-annual trypanocide and ITC campaigns before and after transhumance [16]. However, the majority of cattle-owners are responsible for AAT diagnosis and administration of trypanocidal drugs. The farmers in these communities reported frequent treatment failures. Around a third of communities here, and in cluster 3, attributed treatment failure to misdiagnosis. The evidence as to whether farmer-based diagnosis and treatment is satisfactory is conflicting and will vary between communities depending on experiences and training received $[3,35,41,42]$. In a previous study in Busia in Kenya farmers underestimated the bodyweight of $85.7 \%$ of cattle by an average of $46.9 \%$, which has serious implications for the development of trypanocide resistance [43].

Ideally, livestock owners should be encouraged to use trained veterinarians and veterinary assistants to diagnose and treat the disease. However, an estimated 35 million trypanocide doses are administered every year, large numbers of animals can be affected in certain seasons and many communities with the disease are in more remote areas close to national parks or game reserves where access to veterinary services may be reduced [1]. Training of farmers and selected individuals in the community (CAHWs) can be highly effective to improve diagnosis and ensure correct dosing, although this can be expensive [35]. Following privatisation of the veterinary services in many SSA countries, CAHWs are increasingly used by livestock owners, particularly in remote communities [44]. Providing tools such as weighbands to estimate correct dosing for cattle could also be of use in these communities [43].
Trypanocide resistance was the main reason attributed to treatment failure in cluster 2 , and second most cited reason in clusters 1 and 3. Trypanocide resistance has been reported in most of the regions studied within the five countries $[5,18,45]$. Trypanocide resistance may be linked to under-dosing, or drugs containing insufficient quantities of the active compound. Problems with the drugs were mentioned as a major reason of treatment failure by cluster 1 communities. A study found that $69 \%$ of trypanocides purchased form legal and illegal markets in Cameroon failed to comply with pharmaceutical requirements, with $42 \%$ due to insufficient quantities of the active ingredient [46].

This study only considered AAT and not HAT, in areas where both diseases overlap efforts between animal and public health officers should be coordinated. For example, the Stamp Out Sleeping Sickness (SOS) campaign was a public-private partnership designed to target the cattle reservoir of $T$. $b$. rhodesiense in newly affected areas of Northern Uganda by block treating $>180,000$ head of cattle [23]. Communities in Uganda were also the most likely to keep pigs and the prevalence of $T$. brucei of pigs in the Iganga study area has been reported to be around $8.1 \%$ [47]. Pigs were also important in cluster 2 and have been shown to be affected by $T$. congolense in the Zambian study area, in addition there are an abundance of wildlife hosts for AAT here [25, 48]. Highlighting the need to consider other livestock and wildlife species present when designing AAT control programmes [47].

Vulnerability to AAT is dynamic and complex and contains some level of judgement. The current study is solely based on the experience of farmers, who are usually not involved in the design of control programmes but who suffer the impacts of the disease. One identified key failure from reviews of past control programmes was the inability to transfer responsibility for the control of AAT to cattle-owners once the programme has ceased [36]. Further work is needed to elaborate on reasons why this may be the case. In light of this work a review of AAT control programmes in the countries is now being conducted investigating their success and sustainability [36]. This work also includes interviews with managers of AAT control programmes. In this study engaging with farmers helped raise awareness about the disease and transferred knowledge regarding its control. Soliciting farmers' views and experiences may motivate them to take action themselves and cooperate with externally-led control programmes, increasing their effectiveness. For example, in one of the study area in Zambia, few participants were able to identify a picture of tsetse trap (8.9\%). Following the interviews some farmers said they had seen these traps, but had not known their purpose and that they are often destroyed for their material. 


\section{Conclusions}

This study identified three clusters of community vulnerability profiles within the five countries studied, based on farmers' beliefs with respect to trypanosomiasis control. Further work relating this information to entomological, disease prevalence and data from interviews with AAT control managers is needed to triangulate these results. However, these findings already provide an indication of the ways in which community level variables may impact upon the need, suitability and effectiveness of disease control programmes. Detailed descriptive reports at household-level are also being published, which include information on the demand and willingness to pay for novel treatments and diagnostics under development. Results of this work will be used to develop tailored recommendations, to reduce the impact of AAT in these communities. Including the integration of novel treatments and diagnostics with new and existing programmes, should they become available. The results may also be applicable to other communities with similar profiles to those identified here.

\section{Abbreviations}

AAT: Animal African trypanosomiasis; HAT: Human African trypanosomiasis; MCA: Multiple correspondence analysis; HCA: Hierarchical cluster analysis; MSEG: Mission spéciale pour l'éradication des glossines; CAHW: Community animal health workers

\section{Competing interests}

The authors declare they have no competing interests.

\section{Authors' contributions}

$J G$, RS and GN were responsible for the conception and study design of the project. RS, HRH and CM were responsible for the acquisition of data. $\mathrm{HRH}$, JG and GN were responsible for the conception of this paper, data analysis and drafting of the manuscript. JG and RS critically revised the manuscript. All authors read, provided comments on and gave approval for submission of the final manuscript.

\section{Acknowledgements}

This work was funded by the Department for International Development (DFID) of the UK government as part of GALVmed's Animal African Trypanosomosis Program [DFID Program: Controlling African Animal Trypanosomosis (AAT)] (Aries code 202040-101). The funding body had no role in the study design, collection, analysis, and interpretation of data; the writing of the manuscript; and in the decision to submit the manuscript for publication. The authors would also like to thank the field teams in the various countries particularly Farikou Omarou and Sulani Nyimbili. Finally, they wish to thank Morgane Salines for her help with the data management, Alexander Mastin for his advice on the statistical methods and Georgina Limon, William Gilbert and Christopher Stuart Browne for their valuable comments on the manuscript.

\footnotetext{
Author details

${ }^{1}$ London Centre for Neglected Tropical Disease Research, London, UK 2Department of Production and Population Health, Royal Veterinary College, Hawkshead Lane, North Mymms, Hatfield, Hertfordshire AL9 7TA, UK. ${ }^{3}$ Department of Vector Biology, Liverpool School of Tropical Medicine, Pembroke Place, Liverpool L3 5QA, UK. ${ }^{4}$ School of Veterinary Medicine, University of Zambia, Great East Road Campus, P.O. Box 32379, Lusaka, Zambia. ${ }^{5}$ Global Alliance for Livestock Veterinary Medicines (GALVmed), Doherty Building, Pentlands Science Park, Bush Loan, Edinburgh EH26 OPZ, UK.
}

Received: 18 November 2015 Accepted: 21 January 2016

Published online: 30 January 2016

\section{References}

1. PATTEC. A continental plan of action for the eradication of Tsetse and trypanosomosis. The OAU pathway for the PATTEC. Pan African Tsetse and trypanosomosis Global Veterinaria, Eradication campaign. 2000.

2. Swallow BM. Impacts of trypanosomiasis on African agriculture. PAAT Technical and Scientific Series (FAO). 2000

3. Van den Bossche P, Doran M, Connor R. An analysis of trypanocidal drug use in the Eastern Province of Zambia. Acta trop. 2000;75(2):247-58.

4. McDermott J, Woitag T, Sidibé I, Bauer B, Diarra B, Ouédraogo D, et al. Field studies of drug-resistant cattle trypanosomes in Kénédougou Province, Burkina Faso. Acta Trop. 2003:86(1):93-103.

5. Pinder $\mathrm{M}$, Authie $\mathrm{E}$. The appearance of isometamidium resistant Trypanosoma congolense in West Africa. Acta trop. 1984;41(3):247-52.

6. Shaw APM, Torr SJ, Waiswa C, Cecchi G, Wint GRW, Mattioli RC, et al. Estimating the costs of tsetse control options: An example for Uganda. Prev Vet Medi. 2013;110(3-4):290-303.

7. Hendrickx G, de La Rocque S, Reid R, Wint W. Spatial trypanosomosis management: from data-layers to decision making. Trends Parasitol. 2001; 17(1):35-41.

8. Cecchi G, Paone M, Herrero RA, Vreysen MJ, Mattioli RC. Developing a continental atlas of the distribution and trypanosomal infection of tsetse flies (Glossina species). Parasit Vectors. 2015;8(1):284.

9. Shaw AP. Economic quidelines for strategic planning of tsetse and trypanosomiasis control in West Africa. Food \& Agriculture Org., Rome 2003.

10. Mumford J. Application of benefit/cost analysis to insect pest control using the sterile insect technique. In: Sterile Insect Technique. Springer Netherlands; 2005: 481-498

11. Vale GA, Torr SJ. User-friendly models of the costs and efficacy of tsetse control: application to sterilizing and insecticidal techniques. Med Vet Entomol. 2005;19(3):293-305.

12. Shaw A, Hendrickx G, Gilbert M, Mattioli R, Codjia V, Dao B, et al. Mapping the benefits: a new decision tool for tsetse and trypanosomiasis interventions. Food Agric Org. 2006. http://www.fao.org/3/a-ag015e.pdf

13. Bouyer J, Bouyer F, Donadeu M, Rowan T, Napier G. Community- and farmer-based management of animal African trypanosomosis in cattle. Trends Parasitol. 2013;29(11):519-22.

14. Soudré A, Ouédraogo-Koné S, Wurzinger M, Müller S, Hanotte O, Ouédraogo AG, et al. Trypanosomosis: a priority disease in tsetse-challenged areas of Burkina Faso. Trop Anim Health Pro. 2013;45(2):497-503.

15. MINSANTE, MINEPIA, MINEPAT. Programme national d'eradication des trypanosomoses au cameroun (pro.n.e.try.c). Le Ministre de la Santé Publiqu, Le Ministre de l'Elevage des Pêches et des Industries Animales and Le Ministre de l'Economie, de la Planification et de l'Aménagement du Territoire. 2010.

16. Mamoudou A, Zoli A, Van Den Bossche P, Delespaux V, Cuisance D, Geerts S. Half a century of Tsetse and Animal Trypanosomosis control on the Adamawa Plateau in Cameroon. Rev Elev Med Vet Pays Trop. 2009;62:33-8.

17. Fuller GK. Distribution of Glossina (Diptera: Glossinidae) in south-western Ethiopia. B Entomol Res. 1978;68(02):299-305.

18. Chanie M, Adula D, Bogale B. Socio-economic assessment of the impacts of trypanosomiasis on cattle in Girja District, Southern Oromia Region, Southern Ethiopia. Acta Parasitol Globalis. 2013;4:80-5.

19. Hagos A, Degefa G, Yacob H, Fikru R, Alemu T, Feseha G, et al. Seroepidemiological survey of trypanozoon infection in horses in the suspected dourine-infected Bale highlands of the Oromia region, Ethiopia. Rev Sci Tech. 2010;29(3):649.

20. Co-ordinating office for control of trypansomiasis in Uganda. [http://coctu. go.ug/Tsetse_control.html]

21. Muhanguzi D, Picozzi K, Hattendorf J, Thrusfield M, Kabasa JD, Waiswa $C$, et al. The burden and spatial distribution of bovine African trypanosomes in small holder crop-livestock production systems in Tororo District, south-eastern Uganda. Parasit Vectors. 2014;7(1):1-10.

22. Selby R, Bardosh K, Picozzi K, Waiswa C, Welburn SC. Cattle movements and trypanosomes: restocking efforts and the spread of Trypanosoma brucei rhodesiense sleeping sickness in post-conflict Uganda. Parasit Vectors. 2013;6(1):281.

23. Stamp out sleeping sickness (SOS). [http://www.stampoutsleepingsickness. com/about-sos-.aspx] 
24. Simarro PP, Cecchi G, Paone M, Franco JR, Diarra A, Ruiz JA, et al. The Atlas of human African trypanosomiasis: a contribution to global mapping of neglected tropical diseases. Int J Health Geogr. 2010;9(1):57.

25. Anderson NE, Mubanga J, Fevre EM, Picozzi K, Eisler MC, Thomas R, et al. Characterisation of the wildlife reservoir community for human and animal trypanosomiasis in the Luangwa Valley, Zambia. PLoS Negl Trop Dis. 2011; 5(6):e1211.

26. Buyst $\mathrm{H}$. The epidemiology of sleeping sickness in the historical Luangwa valley. Ann Soc Belg Med Trop. 1977;57(4-5):349-59.

27. Cardona OD, van Aalst MK, Birkmann J, Fordham M, McGregor G, Perez R, et al. Determinants of risk: exposure and vulnerability. In: Managing the Risks of Extreme Events and Disasters to Advance Climate Change Adaptation. A Special Report of Working Groups I and II of the Intergovernmental Panel on Climate Change (IPCC). Cambridge, UK, New York, NY, USA: Cambridge University Press; 2012. p. 65-108.

28. Costard S, Porphyre V, Messad S, Rakotondrahanta S, Vidon H, Roger F, et al. Multivariate analysis of management and biosecurity practices in smallholder pig farms in Madagascar. Prev Vet Med. 2009;92(3):199-209.

29. Simon-Grifé M, Martín-Valls GE, Vilar MJ, García-Bocanegra I, Martín M, Mateu $E$, et al. Biosecurity practices in Spanish pig herds: Perceptions of farmers and veterinarians of the most important biosecurity measures. Prev Vet Med. 2013;110(2):223-31

30. Mamoudou A, Zoli A, Tchoua P. Parasitological prevalence of bovine trypanosomosis in the Faro and Deo division valley of the Adamaoua plateau, Cameroon. Int J Biol Chem Sci. 2009;3(5):1192-7.

31. Miruk A, Hagos A, Yacob HT, Asnake F, Basu AK. Prevalence of bovine trypanosomosis and trypanocidal drug sensitivity studies on Trypanosoma congolense in Wolyta and Dawero zones of southern Ethiopia. Vet Parasitol. 2008;152(1-2):141-7

32. Vreysen MJB, Seck MT, Sall B, Bouyer J. Tsetse flies: Their biology and control using area-wide integrated pest management approaches. J Invertebr Pathol. 2013:112(Supplement 1):S15-25.

33. Solano P, Ravel S, De Meeûs T. How can tsetse population genetics contribute to African trypanosomiasis control? Trends Parasitol. 2010;26(5): 255-63

34. Sow A, Sidibé I, Bengaly Z, Bouyer J, Bauer B, Van den Bossche P. Fifty years of research and fight against tsetse flies and animal trypanosomosis in Burkina Faso. An overview. Inter-African Bureau for Animal Resources Bureau Interafricain des Ressources Animales PO Box 30786, Nairobi, Kenya. 2010;95:95.

35. Grace D, Randolph T, Affognon H, Dramane D, Diall O, Clausen P-H. Characterisation and validation of farmers' knowledge and practice of cattle trypanosomosis management in the cotton zone of West Africa. Acta Trop. 2009;111(2):137-43.

36. al. Me. Past and ongoing T\&T control operations in selected countries (Burkina Faso, Cameroon, Ethiopia, Uganda and Zambia): a review. In preparation

37. Rowlands G, Mulatu W, Leak S, Nagda S, d'leteren G. Estimating the effects of tsetse control on livestock productivity-a case study in southwest Ethiopia. Trop Anim Health Prod. 1999:31(5):279-94.

38. van der Waaij EH, Hanotte O, van Arendonk JAM, Kemp SJ, Kennedy D, Gibson JP, et al. Population parameters for traits defining trypanotolerance in an F2 cross of N'Dama and Boran cattle. Livest Prod Sci. 2003;84(3):219-30.

39. ILCA. Productivity of trypanotolerant livestock. In: Trypanotolerant livestock in West \& Central Africa. International livestock centre for Africa. Addis Ababa, Ethiopia 1992.

40. Agyemang K. Pertinent issues in designing analytical frameworks. Trypanotolerant livestock in the context of trypanosomiasis intervention strategies (Chapter 7, Vol. 7). PAAT Technical and Scientific Series. Food \& Agriculture Org, Rome, 2005

41. Delespaux V, Geerts S, Brandt J, Elyn R, Eisler M. Monitoring the correct use of isometamidium by farmers and veterinary assistants in Eastern Province of Zambia using the isometamidium-ELISA. Vet parasitol. 2002;110(1):117-22.

42. Machila N, Wanyangu SW, MCDermott J, Welburn SC, Maudlin I, Eisler MC. Cattle owners' perceptions of African bovine trypanosomiasis and its control in Busia and Kwale Districts of Kenya. Acta Tropica. 2003;86(1):25-34.

43. Machila N, Fèvre EM, Maudlin I, Eisler MC. Farmer estimation of live bodyweight of cattle: Implications for veterinary drug dosing in East Africa. Prev Vet Med. 2008;87(3-4):394-403.

44. Woodford J. Synergies between veterinarians and para-professionals in the public and private sectors: organisational and institutional relationships that facilitate the process of privatising animal health services in developing countries. Rev Sci Tech OIE. 2004:23(1):115-35. discussion 391-401.

45. Sinyangwe L, Delespaux V, Brandt J, Geerts S, Mubanga J, Machila N, et al. Trypanocidal drug resistance in eastern province of Zambia. Vet Parasitol. 2004;119(2-3):125-35.

46. Teko-Agbo A. Quality of veterinary medicinal products in circulation in cameron and senegal. Dakar: OIE Conference on Veterinary Medicinal Products in Africa; 2008

47. Waiswa C. Porcine trypanosomiasis in southeastern Uganda: prevalence and assessment of therapeutic effectiveness. 2005 [https://www.researchgate. net/publication/228636207_Porcine trypanosomiasis_in_southeastern Uganda_prevalence_and_assessment_of_therapeutic_effectiveness].

48. Simukoko H, Marcotty T, Phiri I, Geysen D, Vercruysse J, Van den Bossche P. The comparative role of cattle, goats and pigs in the epidemiology of livestock trypanosomiasis on the plateau of eastern Zambia. Vet Parasitol. 2007;147(3-4):231-8.

49. Mamoudou A, Zoli A, Tchoua P. Parasitological prevalence of bovine trypanosomosis in the Faro et Deo division valley of the Adamaoua plateau, Cameroon. Int J Biol Chem Sci. 2009;3(5):1192-7.

50. Abdoulmoumini M, Suh PF, Jean EN. Trypanosomes and helminths infections in Mayo Rey Division of Cameroon and impact of concurrent infections on cattle. J Vet Med Anim Health. 2015;7(6):215-20.

51. Tasew S, Duguma R. Cattle anaemia and trypanosomiasis in wes-tern Oromia State, Ethiopia. Rev Méd Vét. 2012;163(12):581-8.

52. Fikru R, Goddeeris BM, Delespaux V, Moti Y, Tadesse A, Bekana M, et al. Widespread occurrence of Trypanosoma vivax in bovines of tsetse- as well as non-tsetse-infested regions of Ethiopia: A reason for concern? Vet Parasitol. 2012;190(3-4):355-61.

53. Mubanga J. Animal trypanosomiasis in the eastern province of Zambia: epidemiology in recently-settled areas and evaluation of a novel method for control. Doctoral dissertation, University of Edinburgh, Edinburgh, UK. 2009

\section{Submit your next manuscript to BioMed Central and we will help you at every step:}

- We accept pre-submission inquiries

- Our selector tool helps you to find the most relevant journal

- We provide round the clock customer support

- Convenient online submission

- Thorough peer review

- Inclusion in PubMed and all major indexing services

- Maximum visibility for your research

Submit your manuscript at www.biomedcentral.com/submit 